\title{
Viabilidade no atendimento às normas do Programa Nacional de Alimentação Escolar e sua relação com custo dos cardápios
}

\author{
Feasibility in meeting nutrient amounts of the National School \\ Feeding Program and its relationship with the menu cost
}

Eliseu Verly-Junior (https://orcid.org/0000-0002-1101-8746) ${ }^{1}$

Dayan Carvalho Ramos Salles de Oliveira (https://orcid.org/0000-0002-2821-7223) ${ }^{1}$

Rafael Lavourinha Pinto (https://orcid.org/0000-0001-8126-5059) ${ }^{1}$

Emanuele Souza Marques (https://orcid.org/0000-0002-8633-7290) ${ }^{1}$

Diana Barbosa Cunha (https://orcid.org/0000-0003-0900-5628) ${ }^{1}$

Flávia Mori Sarti (https://orcid.org/0000-0003-2834-2005) ${ }^{2}$

${ }^{1}$ Instituto de Medicina Social, Universidade do Estado do Rio de Janeiro. R. São Francisco Xavier 524, Maracanã. 20550-900 Rio de Janeiro RJ Brasil. eliseujunior@gmail.com

${ }^{2}$ Escola de Artes, Ciências e Humanidades, Universidade de São Paulo. São Paulo SP Brasil.

\begin{abstract}
We evaluated the feasibility of the menu adequacy regarding the nutritional constraints established by the National School Feeding Program (PNAE) and its relation to the cost. Each menu accounted for a given food combination within each food group. A diet optimization model comprising each set of foods was designed to obtain food quantities in order to meet the exigences of the PNAE at the lowest cost (menus with 20\% and $30 \%$ of dietary reference intake for energy, macronutrients, calcium, iron, magnesium, zinc, vitamins $A$ and $C$, also restrictions for sodium, saturated and trans fats, and added sugar). There was no feasible solution that accommodated all nutrient targets. Limiting components were calcium, sodium, and carbohydrates; but the menus were adequate for the other nutrients. There was a positive correlation between the menu cost and the frequency of meat and fruits, and a negative correlation with the contents of sodium and carbohydrates, and with the frequencies of rice and beans. The probability of obtaining carbohydrate adequacy was close to zero when the meat frequency was higher than one serving per week. In conclusion, it is unlikely to obtain menus that meet all the requirements of the PNAE.

Key words School feeding, Nutrients, Menu planning, Linear programming, Nutritional recommendations
\end{abstract}

Resumo $O$ estudo avaliou a viabilidade da adequação de cardápios em relação às exigências nutricionais estabelecidas pelo Programa Nacional de Alimentação Escolar (PNAE) e a relação entre o custo do cardápio. Cada cardápio semanal contou de uma combinação de alimentos dentro de cada grupo. Para cada combinação de alimentos foi elaborado um modelo de otimização de dados para obter as quantidades de cada alimento de forma a atender às exigências do PNAE ao menor custo possível (cardápios com 20\% e 30\% da ingestão dietética de referência para energia, macronutrientes, cálcio, ferro, magnésio, zinco, vitaminas $A$ e $C$, além de restrições para sódio, gorduras saturada e trans, e açúcar de adição). Não foi obtida nenhuma solução que acomodasse todas as exigências do PNAE. Os componentes limitantes foram cálcio, sódio e carboidratos; para os demais os cardápios foram adequados. O custo foi diretamente correlacionado com a frequência de carne e frutas, e inversamente com os conteúdos de sódio e carboidratos, e com as frequências de arroz e feijão. A probabilidade de adequação de carboidratos foi próxima de zero quando a frequência de carne foi acima de 1 vez por semana. Concluindo, é pouco provável a obtenção de cardápios que atendam à todas as exigencias do PNAE.

Palavras-chave Alimentação escolar, Nutrientes, Planejamento de cardápios, Programação linear, Recomendações nutricionais 


\section{Introdução}

O Programa Nacional de Alimentação Escolar (PNAE) tem o propósito de garantir alimentação adequada a escolares matriculados na rede pública de ensino em todo território nacional. Em relação aos recursos financeiros, o PNAE transfere per capitas diferenciados para atender às diversidades étnicas e as necessidades nutricionais por faixa etária, modalidade de ensino e condição de vulnerabilidade social. Atualmente $o$ repasse governamental varia de $R \$ 0,32$ per capita/dia para Educação de Jovens e Adultos a R\$ 2,00 para o Programa de Fomento às Escolas de Ensino Médio em Tempo Integral. O restante do valor necessário para a execução do programa é de responsabilidade dos municípios que aderem ao PNAE.

Dentre as normas para execução do Programa, destacam-se que os cardápios deverão (i) ser planejados para atender a necessidades nutricionais mínimas, que variam de $20 \%$ a $70 \%$ da ingestão diária recomendada (IDR) de acordo com a modalidade de ensino; (ii) ser atendidas as recomendações de energia, carboidratos, proteínas, lipídios, fibras, vitamina $\mathrm{A}$, vitamina $\mathrm{C}$, cálcio, ferro, magnésio e zinco; e (iii) fornecer, no mínimo, três porções de frutas e hortaliças e não mais que duas porções de doces por semana.

Poucos estudos que avaliaram qualitativa e quantitativamente a adequação dos cardápios apontam para dificuldade dos municípios atenderem às recomendações para todos os nutrientes avaliados ${ }^{1-6}$. A pesquisa "Composição nutricional da alimentação escolar no Brasil, uma análise a partir de uma amostra de cardápios", avaliou uma amostra 1.064 cardápios de escolas atendidas pelo PNAE e apontou alguma inadequação para todos os nutrientes, sendo que, em sua maioria, ficaram abaixo do mínimo exigido pela legislação em pelo menos 50\% dos cardápios $^{5}$.

De fato, a elaboração de cardápios para a alimentação escolar se torna uma tarefa complexa dada a restrição orçamentária. No entanto, o conteúdo de nutrientes dos cardápios pode ser otimizado pela seleção de alimentos fontes dos nutrientes, culturalmente aceitáveis, e cuja inclusão não comprometa os limites orçamentários para execução dos cardápios. A otimização de dados por programação linear é uma ferramenta que auxilia nesta tarefa; é útil para avaliar a viabilidade em diversos contextos (quantidades, tipos, e preços dos alimentos), bem como encontrar a melhor solução matemática para problemas complexos que envolvem múltiplas variáveis e restrições (por exemplo, custo dos alimentos e adequação de nutrientes) ${ }^{7,8}$. Diante do exposto, 0 objetivo deste estudo consiste em avaliar a viabilidade no atendimento às recomendações de quantidades de nutrientes exigidas pelo PNAE. Adicionalmente, será avaliada a relação entre custo e a adequação do cardápio.

\section{Metodologia}

\section{Descrição dos modelos de otimização utilizando programação linear}

Modelos de otimização de dados por programação linear foram desenvolvidos para elaboração de cardápios semanais que atendam a todas as exigências nutricionais do PNAE ao menor custo. O objetivo desta otimização é identificar a melhor solução (combinação de alimentos que comporá o cardápio e suas quantidades) que satisfaça ao conjunto de restrições de adequação nutricional ao menor custo possível. Caso o modelo não retorne uma solução viável (na impossibilidade de obtenção de um cardápio que atenda a todas as exigências do programa), um termo adicional será incluído no modelo para minimizar a diferença entre o a quantidade do nutriente presente no cardápio otimizado e a quantidade desejada ${ }^{9}$. Este termo representa a diferença entre a meta (quantidade a ser atingida no cardápio) do nutriente $n$ e a quantidade possível de se obter, quando a meta não for possível de ser alcançada. Por exemplo, para um dado nutriente cuja meta seja $100 \mathrm{mg}$, uma diferença negativa de $10 \mathrm{mg}$ se refere a um cardápio contendo $90 \mathrm{mg}$ ao invés de $100 \mathrm{mg}$. Da mesma forma, para componentes cuja ingestão deva ser limitada (ex.: sódio, gordura saturada), uma diferença positiva de $10 \mathrm{~g}$ se refere a um cardápio contendo $110 \mathrm{mg}$ ao invés de 100mg. A função objetivo pode ser descrita como segue:

minimizar $\mathrm{y}=$

$$
\sum_{i=1}^{i=g}\left(Q_{i}^{\text {otm }} \cdot \text { preço }_{i}\right)+\sum_{n=1}^{n=N}\left|\frac{\text { nut }_{\mathrm{n}}^{\text {opt }}-\text { meta }_{\mathrm{n}}}{\text { meta }_{\mathrm{n}}}\right|
$$

Onde: $g$ é o número de alimentos; $\mathrm{Q}_{i}^{\text {otm }}$ é a quantidade do alimento $i$ no cardápio otimizado; preço é o preço do alimento por quilo; e nut ${ }_{n}^{\text {opt }}$ é a quantidade do nutriente $n$ mais próxima da meta (quantidade a ser atingida no cardápio). Esta função objetivo minimiza simultaneamente o preço e as diferenças positivas e negativas. 


\section{Variáveis dos modelos de otimização}

Alimentos: referem-se aos alimentos que podem compor os cardápios referentes a uma semana. A lista de alimentos foi obtida a partir de listas de compras de alimentos utilizadas em um município do Estado do Rio de Janeiro. Esta lista contém os alimentos que foram licitados para compor os cardápios relativos ao segundo semestre de 2017. Preparações foram consideradas como um único alimento. Por exemplo, a quantidade de arroz otimizada nos cardápios já levará em consideração a quantidade de óleo e sal utilizados na preparação, bem como sua composição nutricional. Igualmente, para alimentos compostos, como café com leite, foi criado o item composto com uma proporção definida para os alimentos que os compõem, cuja composição nutricional refletirá essa proporção entre os alimentos. Este procedimento foi adotado para evitar que o modelo encontre como solução um cardápio que contenha um alimento que não é usualmente consumido sozinho (por exemplo, o pão deverá vir sempre acompanhado de margarina, manteiga, ou algum outro item). Neste estudo foram considerados 86 itens entre alimentos e preparações.

Preço dos alimentos: foram obtidos por meio de listas de compras dos alimentos licitadas para o segundo semestre de 2017, fornecidas pelo município. Os preços se referem aos alimentos em sua forma bruta (cru e com partes não comestíveis, quando aplicado). O preço dos alimentos compostos e preparações foram calculados considerando os preços de cada alimento ou ingredientes que os compõem. Por exemplo, leite com achocolatado: será considerado que $100 \mathrm{~g}$ da preparação possui $80 \mathrm{~g}$ de leite e $20 \mathrm{~g}$ de achocolatado. O preço da preparação foi a somatória do custo por porção de cada item.

Os tamanhos de porção definidas para cada alimento e preparação, bem como os preços aplicados podem ser consultados no anexo on-line, disponível em www.nebin.com.br/pnae.html.

\section{Restrições impostas aos modelos}

Adequação de nutrientes: refere-se ao conjunto de exigências de nutrientes estabelecidos pelo PNAE. Para este estudo foi utilizado como exemplo o percentual da ingestão diária recomendada (IDR) referentes à educação básica, faixa etária dos alunos de 6 a 10 anos: (20\% da IDR, máximo de 400mg de sódio, 1 refeição/dia; e 30\% da IDR, máximo de 600mg de sódio, 2 refeições/dia)
(Tabela 1). Além disso foram impostas as restrições: máximo de $10 \%$ de energia proveniente de açúcar simples, máximo de $1 \%$ de energia proveniente de gordura trans, máximo de $10 \%$ de energia proveniente de gordura saturada, e entre $15 \%$ e $30 \%$ de energia proveniente de gorduras totais.

\section{Processo de elaboração dos cardápios}

Seleção dos alimentos: Os alimentos foram agrupados em frutas, hortaliças, cereais, leguminosas, carnes, leites e derivados, bolos e pães e doces. A seleção dos alimentos para compor um dado cardápio semanal foi realizada por sorteio, a partir de uma lista de alimentos previamente cadastrados. Como os cardápios podem ser compostos por uma grande variedade de itens dentro de cada grupo, o número de alimentos sorteados em cada grupo de alimento variou conforme as seguintes restrições: derivados de leite, biscoitos, bolos e pães, carnes ( 0 a 5 vezes por semana); frutas, vegetais ( 0 a 10 vezes por semana), arroz e feijão ( 0 a 4 vezes), massas ( 0 a 2 vezes), doces ( 0 a 3 vezes), sucos (0 a 3 vezes). Para os grupos frutas e verduras, foi permitido que cada alimento repetisse no máximo uma vez na mesma semana.

Tabela 1. Ingestão diária recomendada de referência.

\begin{tabular}{|c|c|c|c|}
\hline Nutriente & IDR & $\begin{array}{c}1 \text { refeição } \\
(20 \% \\
\text { IDR })\end{array}$ & $\begin{array}{c}2 \\
\text { refeições } \\
(30 \% \\
\text { IDR }) \\
\end{array}$ \\
\hline & & \multicolumn{2}{|c|}{ Valores Mínimos } \\
\hline Energia (kcal) & 1500 & 300 & 450 \\
\hline Carboidratos (g) & 243.7 & 48.8 & 73.1 \\
\hline Proteínas (g) & 46.7 & 9.4 & 14 \\
\hline Lipídios (g) & 37.7 & 7.5 & 11 \\
\hline Fibras (g) & 26.7 & 5.4 & 8 \\
\hline Vit. A (mcg) & 500 & 100 & 150 \\
\hline Vit. C (mg) & 36.7 & 7 & 11 \\
\hline Cálcio (mg) & 1050 & 210 & 315 \\
\hline Ferro (mg) & 9 & 1.8 & 2.7 \\
\hline Magnésio (mg) & 186.7 & 37 & 56 \\
\hline \multirow[t]{2}{*}{ Zinco (mg) } & 6.7 & 1.3 & 2 \\
\hline & \multicolumn{3}{|c|}{ Valores Máximos } \\
\hline Gord. Saturada (g) & & 3.3 & 5 \\
\hline Gord. Trans (g) & & 0.33 & 0.5 \\
\hline Sódio (mg) & & 400 & 600 \\
\hline Açúcar de adição (g) & & 7.5 & 11.2 \\
\hline
\end{tabular}

Fonte: Resolução n³8/2009 do FNDE. 
A combinação e a frequência dos alimentos que compuseram cada cardápio semanal foram obtidas aleatoriamente em cada execução do modelo, ou seja, para um dado cardápio, foram sorteadas quantidades semanais de itens dentro do estabelecido acima para cada grupo de alimento. Esse processo foi repetido 30.000 vezes para cobrir um grande número de possibilidades de combinações de alimentos. A partir dos alimentos sorteados, o modelo de otimização determinou as quantidades, em gramas, de cada alimento sorteado para cada cardápio de tal forma que fornecesse as quantidades mínimas diárias de cada nutriente ao menor custo possível. Nos cardápios que oferecem somente o almoço foram desconsiderados os alimentos usuais de café da manhã, como pães, bolos, biscoitos, mingaus e achocolatado.

Os alimentos foram considerados nos modelos em sua forma preparada e já descontadas as porções não comestíveis. As quantidades dos alimentos em sua forma bruta, quando aplicável, foram convertidas para quantidades prontas para consumo utilizando fatores de correção e cocção apropriados. Para cada alimento registrado foi calculada a composição centesimal de energia e nutrientes relativa à sua forma pronta para consumo, utilizando a tabela de composição nutricional desenvolvida pelo IBGE para inquéritos nutricionais.

Os modelos de programação linear foram executados com o algoritmo Simplex utilizando o PROC OPTMODEL do SAS OR 9.4. Foram calculadas correlações de Spearman entre o custo dos cardápios, o conteúdo dos nutrientes limitantes e as frequências semanais dos grupos de alimentos.

\section{Resultados}

\section{Cardápios com 20\% da IDR}

Considerando os modelos com restrições fixas para os conteúdos de nutrientes, não foi obtida nenhuma solução que acomodasse todas as restrições. Nos modelos que flexibilizaram o conteúdo mínimo dos componentes, foi identificado como limitantes o cálcio, sódio e carboidratos. Todos os demais componentes (calorias, gorduras totais, trans e saturada, fibras, açúcar de adição, vitaminas A e C, zinco, ferro e magnésio) foram adequados nos cardápios. $O$ percentil 5 do conteúdo de sódio compatível com adequação dos demais componentes foi de 530mg; já os per- centis 95 para cálcio e carboidratos foram 110mg e 50g, respectivamente. Foram obtidos 3.016 cardápios semanais dos 30.000 modelos de otimização executados. O custo per capita diário variou de $\mathrm{R} \$ 0,56$ a $\mathrm{R} \$ 3,65$ (média $\mathrm{R} \$ 1,55$ ); no entanto, o custo foi correlacionado com a frequência de carne e frutas, e inversamente correlacionado com os conteúdos de sódio e carboidratos, e com as frequências de arroz e feijão. A probabilidade de adequação (quantidade de cardápios adequados em relação ao total de cardápios obtidos) para cálcio e sódio foi similar entre as frequências de carnes, legumes e verduras, frutas e doces na semana. No entanto, a probabilidade de adequação de carboidratos foi próxima de zero quando a frequência de carne foi acima de 1 vez por semana (Tabela 2).

\section{Cardápios com 30\% da IDR}

Como nos cardápios contemplando $20 \%$ da IDR, também não houve nenhuma solução que acomodasse todas as restrições dos modelos. $\mathrm{Da}$ mesma forma, os componentes limitantes foram cálcio, sódio e carboidratos. Foram obtidos 1.097 cardápios semanais dos 30.000 modelos de otimização executados. O percentil 5 do conteúdo de sódio compatível com adequação dos demais componentes foi de $635 \mathrm{mg}$; e os percentis 95 para cálcio e carboidratos foram $267 \mathrm{mg}$ e $75 \mathrm{~g}$, respectivamente. $\mathrm{O}$ custo per capita diário variou de $R \$ 1,12$ a $R \$ 4,61$ (média $R \$ 2,57$ ), e foi positivamente correlacionado com a frequência de carne e frutas, e inversamente correlacionado com os conteúdos de cálcio, sódio e carboidratos, além das frequências de arroz e feijão, pães, bolos e biscoitos e alimentos à base de leite. A probabilidade de adequação de cálcio e sódio foi similar entre as frequências semanais de alimentos dentro dos grupos. A probabilidade de adequação de carboidratos foi próxima de zero quando a frequência de carne foi acima de 1 vez por semana (Tabela 3).

\section{Discussão}

Neste estudo foi demonstrado que é pouco provável uma combinação de alimentos em um cardápio que forneça as quantidades de todos os componentes exigidas pelo PNAE. Logo, é provável que grande parte dos cardápios praticados nas escolas, a despeito dos recursos disponíveis para compra dos alimentos, não consiga cumprir com as normas do programa. 
Tabela 2. Custo médio e probabilidade de adequação dos nutrientes limitantes ${ }^{\mathrm{a}}$ de acordo com a frequência semanal dos alimentos. Cardápio com uma refeição diária (20\% da IDR).

\begin{tabular}{lcccc}
\hline Freq. Semanal & $\begin{array}{c}\text { Custo } \\
\text { médio } \\
\text { R\$ }\end{array}$ & Cho & Cálcio & Sódio \\
\hline Carnes & & & & \\
$\quad 0$ a 1 & 1.32 & 0.29 & 0.00 & 0.00 \\
$>1$ a 2 & 1.72 & 0.04 & 0.00 & 0.00 \\
$>2$ & 1.81 & 0.00 & 0.00 & 0.00 \\
Hortaliças & & & & \\
0 a 3 & 1.58 & 0.14 & 0.00 & 0.00 \\
$>3$ a 5 & 1.57 & 0.13 & 0.00 & 0.00 \\
$>5$ a 7 & 1.55 & 0.16 & 0.00 & 0.00 \\
$>7$ & 1.49 & 0.17 & 0.00 & 0.00 \\
Frutas & & & & \\
0 a 1 & 1.18 & 0.11 & 0.00 & 0.00 \\
$>1$ a 2 & 1.49 & 0.17 & 0.00 & 0.00 \\
$>3$ & 1.90 & 0.16 & 0.00 & 0.00 \\
Doces & & & & \\
0 & 1.58 & 0.10 & 0.00 & 0.00 \\
$>0$ a 1 & 1.55 & 0.17 & 0.00 & 0.00 \\
$>1$ & 1.43 & 0.24 & 0.00 & 0.00 \\
\hline
\end{tabular}

${ }^{a}$ Nutrientes cuja adequação não foi possível alcançar em todos os cardápios.
Foram obtidas soluções somente nos modelos que permitiram flexibilizar as exigências para cálcio e sódio, ou seja, pela adição de um termo de desvio na função objetivo. Em relação ao cálcio, estudos descrevem o café da manhã como a refeição que mais fornece este nutriente por usualmente conter alimentos derivados de leite ${ }^{10}$. Nos cardápios com $30 \%$ da IDR, os alimentos à base de leite contribuíram em média com $60 \%$ do total de cálcio diário (dados não mostrados). Por este motivo, sua adequação nos cardápios com $20 \%$ da IDR, que não incluem café da manhã, torna-se mais difícil de ser alcançada comparada aos cardápios com 30\% da IDR. Assim, a assunção de um mesmo percentual da IDR para todos os nutrientes deve ser avaliada segundo a composição dos alimentos que tipicamente compõem as refeições. Cabe contextualizar, entretanto, que a recomendação de ingestão diária de cálcio não é atingida por mais de $90 \%$ dos brasileiros ${ }^{11,12}$ e parece ser pouco provável de ser atingida considerando o padrão de consumo da população ${ }^{13}$. A adequação demandaria uma composição de cardápio que pode não ser realística, violando um dos princípios da política de alimentação escolar
Tabela 3. Custo médio e probabilidade de adequação dos nutrientes limitantes ${ }^{\mathrm{a}}$ de acordo com a frequência semanal dos alimentos. Cardápio com duas refeições diárias (30\% da IDR).

\begin{tabular}{|c|c|c|c|c|}
\hline Freq. Semanal & $\begin{array}{c}\text { Custo } \\
\text { médio } \\
\text { R\$ }\end{array}$ & Cho & Cálcio & Sódio \\
\hline \multicolumn{5}{|l|}{ Carnes } \\
\hline 0 a 1 & 2.10 & 0.46 & 0.01 & 0.02 \\
\hline$>1$ a 2 & 2.45 & 0.06 & 0.00 & 0.04 \\
\hline$>2$ a 3 & 2.73 & 0.00 & 0.00 & 0.01 \\
\hline$>3$ & 3.22 & 0.00 & 0.00 & 0.00 \\
\hline \multicolumn{5}{|l|}{ Hortaliças } \\
\hline 0 a 3 & 2.53 & 0.18 & 0.00 & 0.01 \\
\hline$>3$ a 6 & 2.67 & 0.14 & 0.01 & 0.01 \\
\hline$>6$ a 10 & 2.54 & 0.18 & 0.00 & 0.01 \\
\hline$>10$ & 2.51 & 0.19 & 0.01 & 0.02 \\
\hline \multicolumn{5}{|l|}{ Frutas } \\
\hline 0 a 2 & 1.89 & 0.19 & 0.01 & 0.00 \\
\hline$>2$ a 4 & 2.31 & 0.19 & 0.00 & 0.02 \\
\hline$>4$ a 6 & 2.70 & 0.14 & 0.00 & 0.02 \\
\hline$>6$ & 3.12 & 0.18 & 0.00 & 0.02 \\
\hline \multicolumn{5}{|l|}{ Doces } \\
\hline 0 & 2.54 & 0.18 & 0.01 & 0.02 \\
\hline 1 & 2.57 & 0.16 & 0.00 & 0.01 \\
\hline 2 & 2.76 & 0.13 & 0.00 & 0.01 \\
\hline \multicolumn{5}{|l|}{$\begin{array}{l}\text { Pães, bolos, } \\
\text { biscoitos }\end{array}$} \\
\hline 0 & 2.68 & 0.14 & 0.01 & 0.01 \\
\hline 1 & 2.50 & 0.14 & 0.00 & 0.03 \\
\hline$>2$ & 2.32 & 0.32 & 0.00 & 0.02 \\
\hline \multicolumn{5}{|l|}{ Base de leite } \\
\hline 0 a 1 & 2.77 & 0.09 & 0.00 & 0.00 \\
\hline$>1 \mathrm{a} 3$ & 2.60 & 0.17 & 0.00 & 0.02 \\
\hline$>3$ & 2.34 & 0.25 & 0.01 & 0.02 \\
\hline
\end{tabular}

${ }^{a}$ Nutrientes cuja adequação não foi possível alcançar em todos os cardápios.

de valorizar alimentação regional. Em relação ao sódio, os resultados devem ser interpretados com ressalva uma vez que os maiores contribuintes, o arroz e o feijão, fornecem em média 55\% do total de sódio diário (dados não mostrados). Assim, quanto menos sódio utilizado nas preparações, maior a probabilidade de adequação. As exigências para o conteúdo de carboidrato também foram flexibilizadas. Entretanto, cardápios com adequação para carboidratos foram obtidos somente quando a frequência de carne foi baixa, com maior probabilidade de adequação cardápios com até uma porção de carne por semana. Quanto mais carne, mais calorias provenientes 
de gorduras e proteínas, o que reduz o espaço para carboidratos dentro do limite de calorias estabelecido.

Não é possível, no entanto, fazer uma comparação direta entre estes resultados e estudos que avaliaram a adequação dos cardápios. Primeiro, trata-se de um estudo teórico, em que são apresentadas as soluções possíveis dentro de um espectro de alimentos e suas frequências, compatível com o padrão de alimentos e cardápios já descritos na literatura. $\mathrm{O}$ estudo mais abrangente, que avaliou 1.604 cardápios em municípios no Brasil ${ }^{5}$, descreve inadequações para todos os macronutrientes e micronutrientes, mas não permite associar a composição dos cardápios com as inadequações.

A grande variação nos custos dos cardápios implica que é possível obter cardápios adequados para a maioria dos componentes a custos menores. De uma forma geral, cardápios com mais carnes e com mais frutas foram os mais caros, mas não necessariamente mais adequados. A quantidade de hortaliças não influenciou nos preços; logo, num cenário de restrição orçamentária que impede oferta regular de frutas, maior oferta de hortaliças se torna uma opção interessante.

$\mathrm{O}$ repasse aos municípios que aderem ao PNAE (R\$ 0,36 por aluno/dia para esta modalidade de ensino - educação básica, faixa etária dos alunos de 6 a 10 anos de idade - para ambos 20\% e $30 \%$ da IDR) correspondeu, em média, a $23 \%$ (uma refeição) e 14\% (duas refeições) do total do custo do cardápio per capita/dia. Ainda que seja o mesmo valor de repasse, cardápios com $30 \%$ da IDR foram, em média, $65 \%$ mais caros comparados àqueles com $20 \%$ da IDR. Logo, especialmente nos municípios com maior restrição orçamentária, ofertar minimamente os nutrientes nas quantidades exigidas pelo programa se torna uma tarefa difícil, principalmente para os cardápios com $30 \%$ da IDR, já que fica a cargo dos municípios complementar o valor para aquisição dos alimentos.
Algumas questões metodológicas referentes ao presente estudo devem ser consideradas. Primeiro, deve-se destacar que o modelo de otimização encontra a melhor solução matemática para um problema definido, cujas assunções são impostas a partir da literatura ou de julgamento pessoal. Neste estudo, optou-se por analisar várias combinações de quantidades de alimentos dentro das frequências semanais previamente definidas para cada grupo. Desta forma foi possível verificar a adequação dentro de um padrão realístico de composição de cardápio. Segundo, a seleção dos alimentos se deu por sorteio; em um cenário real, deve-se observar se os alimentos selecionados também seguem preferências locais ou particularidades dos municípios, o que pode limitar a capacidade de flexibilizar o custo. Ainda que a lista de alimentos utilizada tenha sido obtida de um único município, os itens que a compõem são contemplados pelos alimentos mais consumidos no $\mathrm{Brasil}^{14}$, e que já compõem os cardápios da alimentação escolar no país. Por fim, embora os preços dos alimentos aqui utilizados se refiram ao final do primeiro semestre de 2017, é possível fazer uma comparação com os valores de repasse para os municípios pelo FNDE que eram vigentes neste mesmo período.

Os modelos de otimização aqui utilizados também podem ser utilizados na elaboração de cardápios. É possível customizar o modelo para inclusão, exclusão ou modificação dos alimentos, atualização dos preços, bem como adaptação das restrições para atender a demandas locais. Por exemplo, pode-se definir um custo máximo e otimizar o conteúdo de nutrientes. Se informações sobre preferência dos alimentos por parte dos estudantes forem disponíveis é possível incluí-las ao modelo para obtenção de cardápios mais realísticos.

Concluindo, este estudo mostra o quão é improvável a obtenção de cardápios que atendam a todas as normas do PNAE. Cálcio e sódio foram os nutrientes limitantes para atingir as exigências do programa. 


\section{Colaboradores}

E Verly-Junior trabalhou na concepção do estudo, análise dos dados, redação do manuscrito. DCRS Oliveira trabalhou na revisão e redação do manuscrito. RL Pinto trabalhou na revisão e redação do manuscrito. DB Cunha trabalhou na revisão e redação do manuscrito. ES Marques trabalhou na revisão e redação do manuscrito. FM Sarti trabalhou na revisão e redação do manuscrito.

\section{Referências}

1. Issa RC, Moraes LF, Francisco RR, Santos LC, Anjos AFV, Pereira SCL. Alimentação escolar: planejamento, produção, distribuição e adequação. Rev Panam Salud Publica 2014; 35(2):96-103.

2. Abranches MV, Paula HAA, Mata GMSC, Salvador BC, Marinho MS, Priore SE. Assessment of diet adequacy at public and private day care centers within the national program of school feeding. Nutrire 2009; 34(2):43-57.

3. Neitzke L, Molina MDCB, Salaroli LB. Adequação nutricional da alimentação escolar em município rural - Espírito Santo, Brasil. Nutrire 2012; 37(1):1-12.

4. Silva MMDC, Gregório EL. Avaliação da composição nutricional dos cardápios da alimentação escolar das escolas da rede municipal de Taquaraçu de Minas MG. HU Rev 2012; 37(3):387-394.

5. Brasil. Ministério da Educação (MEC). Fundo Nacional de Desenvolvimento da Educação. Diretoria de Ações Educacionais. Coordenação-Geral do Programa Nacional de Alimentação Escolar. Resumo Executivo. Composição nutricional da alimentação escolar no Brasil: Uma Análise a partir de uma amostra de cardápios - 2011. Brasília: MEC, Fundo Nacional de Desenvolvimento da Educação; 2012.

6. Rossato BM, Storck CR. Adequação Nutricional Da Alimentação Escolar Oferecida Em Instituições De Ensino Da Rede Estadual. Disciplinarum Scientia Cien Saude 2016; 17(1):73-78.

7. Maillot M, Vieux F, Ferguson EF, Volatier J-L, Amiot MJ, Darmon N. To meet nutrient recommendations, most French adults need to expand their habitual food repertoire. J Nutr 2009; 139(9):1721-1727.

8. Maillot M, Monsivais P, Drewnowski A. Food pattern modeling shows that the 2010 Dietary Guidelines for sodium and potassium cannot be met simultaneously. Nutr Res 2013; 33(3):188-194.

9. Ferguson EL, Darmon N, Fahmida U, Fitriyanti S, Harper TB, Premachandra IM. Design of optimal food-based complementary feeding recommendations and identification of key "problem nutrients" using goal programming. J Nutr 2006; 136(9):23992404.

10. Peters BSE, Verly-Jr E, Marchioni DML, Fisberg M, Martini LA. The influence of breakfast and dairy products on dietary calcium and vitamin $\mathrm{D}$ intake in postpubertal adolescent and young adults. J Hum Nutr Diet 2011; 25(1):69-74.

11. Araujo MC, Bezerra IN, Barbosa FS, Junger WL, Yokoo EM, Pereira RA, Sichieri R. Macronutrient consumption and inadequate micronutrient intake in adults. Rev Saúde Pública 2013; 47(1):S177-S189.

12. Fisberg MR, Marchioni DML, Castro MA, Verly-Junior E, Araujo MC, Bezerra IN, Pereira RA, Sichieri R. Ingestão inadequada de nutrientes na população de idosos do Brasil: Inquérito Nacional de Alimentação 2008-2009. Rev Saúde Pública 2013; 47(1):S222-S230.

13. Santos Q, Sichieri R, Darmon N, Matthieu M, Verly-Junior E. Food choices to meet nutrient recommendations for the adult Brazilian population based on the linear programming approach. Public Health Nutr 2018; 21(8):1538-1545. 
14. Souza AM, Pereira RA, Yokoo EM, Levy RB, Sichieri R. Alimentos mais consumidos no Brasil: Inquérito Nacional de Alimentação 2008-2009. Rev Saúde Pública 2013; 47(1):S190-S195.

Artigo apresentado em 08/08/2018

Aprovado em 30/04/2019

Versão final apresentada em 02/05/2019

Editores chefes: Romeu Gomes, Antônio Augusto Moura da Silva 